\title{
Review of 113 cases of autoimmune disorders in pregnancy
}

\author{
Maheswari S., Poornima C.*, Seetha Panicker
}

Department of Obstetrics and Gynecology, PSG Institute of Medical Sciences and Research, Coimbatore, Tamil Nadu, India

Received: 23 September 2019

Accepted: 31 October 2019

\section{*Correspondence:}

Dr. Poornima C.,

E-mail: kavint43@gmail.com

Copyright: ( $)$ the author(s), publisher and licensee Medip Academy. This is an open-access article distributed under the terms of the Creative Commons Attribution Non-Commercial License, which permits unrestricted non-commercial use, distribution, and reproduction in any medium, provided the original work is properly cited.

\section{ABSTRACT}

Background: Autoimmune disorders are chronic multisystem disorders affecting women of their reproductive age. Pregnancy among these women is complicated by the disease itself. Flaring up of disease, uteroplacental insufficiency due to vasculitis and drugs used for treatment are main reason for unfavourable pregnancy outcomes. The objective of this study was to analyze the pregnancy complications and outcome among 113 cases of autoimmune disorders.

Methods: This study is a retrospective analysis of case records of pregnant women with autoimmune disorders. This study was conducted at PSG IMSR and Hospital, Coimbatore, and Tamil Nadu from July 2012 to June 2018. The case sheets were retrieved from medical record department and the details such as type of disease, maternal age, parity, status of disease at conception, treatment taken during pregnancy, maternal complications and fetal complications were collected and analyzed.

Results: During 6-year period there were 113 pregnant women with autoimmune disorders, and they were studied of their previous and present pregnancy outcome. The disease incidence was $7.01 \%$ per 1000 deliveries. $40.7 \%$ were less than 25 years age group and $71.6 \%$ were multigravidae. We had forty-one patients (36\%) who were positive for APLA syndrome which were the maximum number of patients with auto immune disorder in pregnancy and 37 patients (32.7) with SLE. We had significant numbers of maternal and fetal complications for common disorders. Most of the rare auto immune disorders were diagnosed before pregnancy and these pregnancies were managed by multi-disciplinary approach, and continued on immunomodulators throughout pregnancy, hence maternal and fetal complications were less for them.

Conclusions: Adequate pre-conceptional counseling, vigilant monitoring during pregnancy and post-partum will avoid pregnancy related complications and have favorable outcomes.

Keywords: Autoimmune disorder, Fetal complications, Immunomodulators, Maternal complications, Pregnancy outcome, Pre-conceptional counseling

\section{INTRODUCTION}

Autoimmune disorders are chronic multisystem disorders which are characterized by tissue damage and inflammation due to alteration of adaptive immune response in the absence of trigger. ${ }^{1}$ Its prevalence is between $7.6 \%-9.4 \% .^{2}$ Since most of the autoimmune disorders are diagnosed frequently during reproductive age in females, these women are at high risk not only during pregnancy but also during postpartum. ${ }^{3}$ When compared to females without autoimmune disorders, these women carry more incidence of miscarriages in all trimesters, preeclampsia, intrauterine growth restriction, premature rupture of membranes, placental insufficiency, preterm labour, low birth weight and have increased caesarean section rates. ${ }^{4}$ Though these pregnancies carry 
high incidence of adverse effects, improved care in terms of pre-conceptional counselling and continuation of treatment throughout the pregnancy and post-partum have improved the outcome of pregnancies. ${ }^{5}$

\section{METHODS}

This study is a retrospective analysis of a total 113 case records of pregnant women with autoimmune disorders. This study was conducted at PSG IMSR and Hospital, Coimbatore, Tamil Nadu from July 2012 to June 2018. The case sheets were retrieved from medical record department and the details such as type of autoimmune disorder, maternal age, parity, status of disease at conception, treatment taken during pregnancy, maternal complications like pregnancy induced hypertension, gestational diabetes mellitus, thrombotic events, anemia, renal flares, thrombocytopenia, preterm labour, mode of delivery, indications for caesarian section and fetal complications like abortion, anomalies, intra uterine fetal demise, low birth weight, intra uterine growth restriction, oligohydramnios, need for admission to neonatal intensive care unit, low Apgar score were collected and analyzed.

\section{Inclusion criteria}

- All primigravidae and multigravidae who are known case of autoimmune disorder and all primigravidae and multigravidae who are diagnosed with autoimmune disorder during present pregnancy.

\section{Exclusion criteria}

- Pregnant mothers without autoimmune disorders.

\section{RESULTS}

During this period of 6 years (2012-2018), there were 113 pregnant women with autoimmune disorders and study was carried out based on their previous and present pregnancy outcomes. The incidence of autoimmune disorders in pregnancy was $7.01 \%$ per 1000 deliveries.

Table 1 shows the number of pregnancies with autoimmune disorders in our study.

Table 1: Number of pregnancies with autoimmune disorders and percentage.

\begin{tabular}{|lll|}
\hline Type of disorders & $\begin{array}{l}\text { No. of } \\
\text { cases }\end{array}$ & $\%$ \\
\hline Antiphospholipid antibody syndrome & 41 & 36.2 \\
\hline Systemic lupus erythematoses & 37 & 32.7 \\
\hline Idiopathic thrombocytopenic purpura & 11 & 9.7 \\
\hline Takayasu syndrome & 5 & 4.4 \\
\hline Sjögren syndrome & 4 & 3.5 \\
\hline Hashimoto's thyroiditis & 3 & 2.6 \\
\hline Multiple sclerosis & 3 & 2.6 \\
\hline Rheumatoid arthritis & 2 & 1.7 \\
\hline Schönlein-henoch purpura & 2 & 1.7 \\
\hline GBS & 1 & 0.8 \\
\hline Von Williebrand disease & 1 & 0.8 \\
\hline Multisystem connective tissue disorder & 1 & 0.8 \\
\hline Medial vessel vasculitis & 1 & 0.8 \\
\hline Ulcerative colitis & 1 & 0.8 \\
\hline
\end{tabular}

In our study, we had forty-one patients (36\%) with APLA syndrome including primary and secondary APLA and 37 patients $(32.7 \%)$ with SLE.

\section{Table 2: Age group.}

\begin{tabular}{|lll|}
\hline Age in years & No. of cases & $\%$ \\
\hline$<25$ & 46 & 40.7 \\
\hline $25-30$ & 45 & 39.8 \\
\hline $31-35$ & 21 & 18.5 \\
\hline$>35$ & 1 & 0.8 \\
\hline
\end{tabular}

Table 3: Most common autoimmune disorders their maternal complications.

\begin{tabular}{|lllllllll|}
\hline $\begin{array}{l}\text { Type of } \\
\text { disorder }\end{array}$ & PIH & GDM & $\begin{array}{l}\text { Renal } \\
\text { flare }\end{array}$ & Anemia & Thrombocytopenia & $\begin{array}{l}\text { Thrombotic } \\
\text { event }\end{array}$ & $\begin{array}{l}\text { Cesarean } \\
\text { section }\end{array}$ & PTL \\
\hline APLA & $2(4.8 \%)$ & $\begin{array}{l}13 \\
(31 \%)\end{array}$ & $1(2 \%)$ & $3(7.3 \%)$ & - & - & $7(17 \%)$ & $1(2.4)$ \\
\hline SLE & $4(10.8 \%)$ & $6(16 \%)$ & $3(8 \%)$ & $2(5.4 \%)$ & - & $1(2.7 \%)$ & $16(43 \%)$ & $8(21 \%)$ \\
\hline ITP & $1(9 \%)$ & $6(54 \%)$ & - & $1(9 \%)$ & $2(18 \%)$ & - & $7(63 \%)$ & $1(9 \%)$ \\
\hline Takayasu & $3(60 \%)$ & - & $1(20 \%)$ & - & - & - & $4(80 \%)$ & - \\
\hline $\begin{array}{l}\text { Sjögren } \\
\text { syndrome }\end{array}$ & - & $1(25 \%)$ & - & - & - & - & $3(75 \%)$ & - \\
\hline
\end{tabular}

In our study, most of the patients were below 30 years of age. Table 2 shows the age group distribution. Multigravida $(71.6 \%)$ were more in number than primigravida $(28.3 \%)$ in our study.
Parity distribution is shown in Figure 1.

Table 3 shows the most common autoimmune disorders in our study and their maternal complications. 


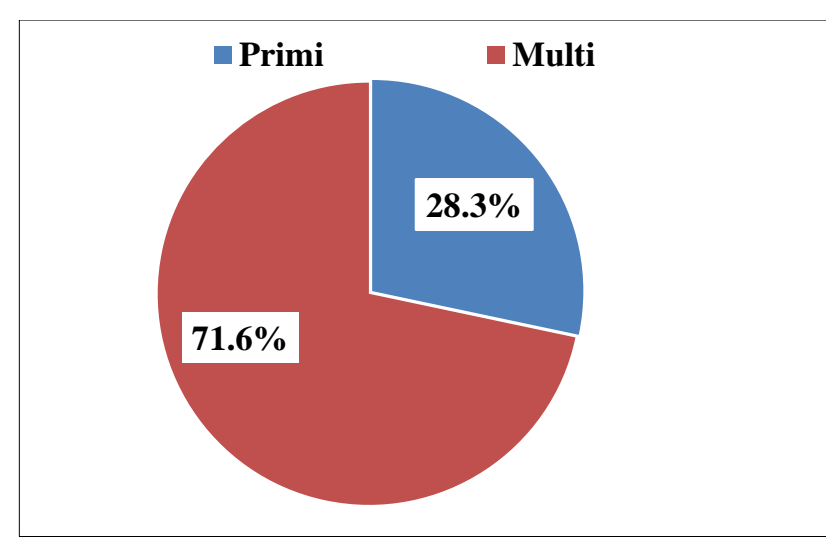

Figure 1: Parity distribution.

Table 4: Fetal complications in previous pregnancy.

\begin{tabular}{|lll|}
\hline Type of disease & Abortion & IUD \\
\hline APLA & $26(63 \%)$ & $9(21.9 \%)$ \\
\hline SLE & $22(59 \%)$ & $5(13.5 \%)$ \\
\hline ITP & $4(36 \%)$ & - \\
\hline Takayasu & - & $1(20 \%)$ \\
\hline Sjögren syndrome & $3(75 \%)$ & - \\
\hline
\end{tabular}

Two patients diagnosed with SLE had abnormal doppler changes at 32 weeks and 34 weeks respectively and underwent caesarean section. The most common indication for caesarean section was non-progression of labour followed by previous section.

Table 4 shows fetal complications in previous pregnancy for more common disorders in our study.

Table 5: Fetal complications in the current pregnancy.

\begin{tabular}{|llll|}
\hline $\begin{array}{l}\text { Type of } \\
\text { disease }\end{array}$ & IUGR & Oligohydramnios & $\begin{array}{l}\text { NICU } \\
\text { admission }\end{array}$ \\
\hline APLA & $7(17 \%)$ & $2(4.8 \%)$ & $1(2.4 \%)$ \\
\hline SLE & $13(35 \%)$ & $6(16 \%)$ & $5(13.5 \%)$ \\
\hline ITP & $2(18 \%)$ & - & $1(9 \%)$ \\
\hline Takayasu & $3(60 \%)$ & - & - \\
\hline $\begin{array}{l}\text { Sjögren } \\
\text { syndrome }\end{array}$ & - & $2(50 \%)$ & - \\
\hline
\end{tabular}

Table 5 shows the fetal complications in the current pregnancy for same disorders.

Table 6: Maternal complications associated with SLE.

\begin{tabular}{|lll|}
\hline Complication & Our study & Eman et al study \\
\hline Pre-eclampsia & $10.8 \%$ & $13 \%$ \\
\hline GDM & $16 \%$ & NA \\
\hline Renal flare & $8 \%$ & NA \\
\hline Anemia & $7.3 \%$ & $21 \%$ \\
\hline C-section & $43 \%$ & $53 \%$ \\
\hline Preterm labour & $21 \%$ & $21 \%$ \\
\hline
\end{tabular}

Table 7: Fetal complications associated with SLE.

\begin{tabular}{|lll|}
\hline Complication & Our study & Eman et al study \\
\hline $\begin{array}{l}\text { Abortion in } \\
\text { previous conception }\end{array}$ & $59 \%$ & $46 \%$ \\
\hline IUD & $13.5 \%$ & $8 \%$ \\
\hline IUGR & $35 \%$ & $32 \%$ \\
\hline LBW & $24.3 \%$ & $22 \%$ \\
\hline NICU admission & $13.5 \%$ & $15 \%$ \\
\hline
\end{tabular}

\section{DISCUSSION}

\section{APLA}

Obstetric antiphospholipid antibody syndrome (OB-APS) is defined according to the updated Sydney classification criteria developed by expert consensus agreement in 2006. ${ }^{6}$ APLs include the lupus anticoagulant, anticardiolipin IgG and IgM and anti- $\beta 2$-glycoprotein I antibody. In addition to the detection of aPLs on at least two occasions more than 12 weeks apart, OB-APS is defined by any one of the following adverse pregnancy outcomes: 1) otherwise unexplained recurrent pregnancy loss before the $10^{\text {th }}$ week of gestation, 2) otherwise unexplained fetal death $\geq 10$ weeks of gestation, 3) preterm birth before 34 weeks of gestation due to preeclampsia or placental insufficiency. ${ }^{7}$ Other OB-APS complications include catastrophic APS, thrombosis, HELLP syndrome (hemolysis, elevated liver enzymes, and low platelet count), IUGR, fetal distress, premature rupture of membranes, and thrombocytopenia. ${ }^{8}$ It has been recognized that among the three aPLs, lupus anticoagulant (LAC) is the primary predictor of poor pregnancy outcome in women both with or without SLE, and with or without other aPLs. ${ }^{9}$ Among the 41 patients with APLA, 20 patients were positive for lupus anticoagulant antibody, 11 were positive for anticardiolipin antibody and 10 had anti- $\beta 2$-glycoprotein I antibody.

In our study, $31.8 \%$ of patients with primary APLA and $4.4 \%$ of patients with secondary APLA with associated SLE were diagnosed. The incidence of pre-eclampsia among APLA positive patients in our study was $4.8 \%$ whereas in Wijeyaratne study, it was $10.9 \% .^{10}$ Similarly the incidence of GDM in our study was $31 \%$ as compared to $19.2 \%$ in Wijeyaratne study. In our study $2.4 \%$ had preterm labour and $17 \%$ of patients underwent cesarean section. In regard to fetal complications, $63 \%$ of patients in our study had previous one or more abortions which was comparable to Wijeyratne study (59.8\%). The incidence of IUD in previous pregnancy was $21.9 . \%$. The incidence of low birth weight babies was $12 \%$ and babies requiring NICU admission was $2.4 \%$ respectively.

\section{SLE}

Systemic lupus erythematosus (SLE, or "lupus"), affects females in a 9:1 ratio to males. ${ }^{11}$ The adverse pregnancy 
outcomes observed with lupus are well known, and include increased rates of intrauterine growth restriction (IUGR), preterm birth and fetal loss, as well as the syndrome of neonatal lupus (NL), associated with trans placental passage of auto antibodies. The risks for thrombosis, infection, thrombocytopenia, and transfusion were each 3- to 7-fold higher for women with systemic lupus erythematosus. Lupus patients also had a higher risk for cesarean sections (odds ratio: 1.7), preterm labor (odds ratio: 2.4), and preeclampsia (odds ratio: 3.0 ) than other women. Women with systemic lupus erythematosus are more likely to have other medical conditions, including diabetes, hypertension, and thrombophilia, that are associated with adverse pregnancy outcomes. ${ }^{12}$

High disease activity at the time of conception or in the months preceding conception is an independent predictor for increased risk of adverse pregnancy outcomes including prematurity, IUGR and fetal demise. This has led to the current recommendations that lupus patients achieve 6 months of disease quiescence prior to attempting conception. ${ }^{13}$ Maternal and fetal complications associated with SLE were compared with Eman et al study. ${ }^{14}$ These are shown in table 6 and 7 respectively.

Six patients had first trimester abortions in the current pregnancy.

\section{Takayasu syndrome}

In our study, $60 \%$ patients had hypertension complicating pregnancy whereas in Mandal et al study had $92.8 \% . .^{15}$ Caesarean section rate in our study was $60 \%$, whereas in Mandal study it was $71.4 \%$. Intrauterine growth restriction was $60 \%$ in our study, which was comparable with Mandal et al study (51.7\%).

\section{Schönlein-henoch purpura}

Schönlein-henoch purpura (SHP) is a systemic vasculitis that affects vessels of a small caliber. ${ }^{16}$ The onset of SHP during pregnancy is very rare. Treatment with orally administered corticosteroids may lead to a beneficial outcome for both mother and newborn. ${ }^{17}$ In our study, we had 2 patients diagnosed with Schönlein-Henoch purpura, of which one developed GDM, other had uneventful pregnancy.

\section{Medium vessel vasculitis}

Most of the women with medium vessel vasculitis fared well during pregnancy without significant disease progression, but instances of aneurysm rupture, renal insufficiency, pulmonary embolism, and myocardial infarction were reported in Gatto et al study. ${ }^{18}$ In our study, one patient diagnosed with medium vessel vasculitis developed myocarditis during pregnancy and she was managed with steroids.

\section{ITP}

Nine percent of chronic ITP patients in our study had preeclampsia, whereas Diego et al, study had $8.3 \% .{ }^{19}$ In our study $9 \%$ had preterm labour which was comparable to Diego et al $(9.5 \%)$ study. Diego et al showed $8.5 \%$ of gestational diabetes in the study whereas in our study we had $54 \%$ of gestational diabetes which could be explained by ethnicity and usage of steroids.

In Yassaee et al, study occurrence of IUGR was $10.5 \%$ whereas in our study it was $18 \%$, among which one baby was admitted in NICU. ${ }^{20}$ In Yassaee et al study $57 \%$ of patients had moderate thrombocytopenia (more than 50,000 ) whereas $18 \%$ of thrombocytopenia and $9 \%$ of anemia were diagnosed in our study.

When comparing the caesarean section rate, Yassaee et al had $81 \%$ whereas we had $63 \%$.

\section{Rheumatoid arthritis}

In women with well-controlled RA, pregnancy outcomes are comparable to the general obstetric population, whereas in women with higher RA disease activity, there is more chances of less favorable pregnancy outcomes. $^{21,22}$

Akasbi et al, study showed improved maternal and fetal outcome in patients with RA in pregnancy. Similarly, in our study two patients diagnosed with RA had uneventful pregnancy.

\section{Guillain-barré syndrome}

Guillain-barré syndrome (GBS) represents a heterogeneous group of immune mediated peripheral neuropathies. A feature common to all GBS variants is a rapidly evolving polyradiculoneuropathy preceded by a triggering event, most often an infection. GBS generally manifests as a symmetric motor paralysis with or without sensory and autonomic disturbances. Delayed diagnosis is common in pregnancy or immediate post-partum period because the initial non-specific symptoms may mimic changes in pregnancy. GBS should be considered in any pregnant patient complaining of muscle weakness, general malaise, tingling of the fingers, and respiratory difficulty. ${ }^{23,24}$

We had one patient diagnosed with GBS who had an uneventful course during pregnancy.

\section{Multiple sclerosis}

Multiple sclerosis (MS) is an inflammatory disease in which the fatty myelin sheaths around the axons of the brain and spinal cord are damaged, leading to demyelination and scarring as well as a broad spectrum of signs and symptoms. ${ }^{25}$ Pregnancy is typically a stabilizing period in the clinical course of MS. During the 
third trimester the MS relapse rate can be $70 \%$ lower when compared with the time prior to pregnancy, but exaggeration of the disease is commonly seen postpartum. Presently, there is no evidence that MS patients are more susceptible to pregnancy or delivery related complications, such as ectopic pregnancy, preeclampsia, gestational diabetes mellitus, prolonged labour or miscarriage than women in general, nor is their infants more likely to be delivered preterm or to be of low birth weight, have malformations or experiences an early death. ${ }^{26,27}$ Mothers with MS required operative delivery more often than healthy mothers, which might be attributed to MS-related symptoms such as neuromuscular perineal weakness and spasticity in addition to fatigue and exhaustion. ${ }^{28}$ In our study, we had 3 mothers diagnosed with multiple scelerosis, of them one developed PIH, one had GDM.

\section{Sjögren syndrome}

Sjögren syndrome is known to occur predominantly in women. Affected women are likely to experience more complicated pregnancies than are women without the disease. ${ }^{29}$ Its effect on pregnancy differs according to the maternal disease, disease activity, and severity of organ damage, antibody profile, and drug treatment.6.

Several studies have reported an increased rate of spontaneous abortion and fetal loss associated with Sjögren syndrome. ${ }^{30}$ This may be explained by, first, the age of the patients at the time of concep-tion which usually belongs to an elderly age group and, second, a possible immunologic factor involved in the mechanisms of miscarriage. ${ }^{31}$

In our study, out of four mothers diagnosed with Sjögren syndrome, two had spontaneous abortions.

The outcome of pregnancies in women with Sjögren syndrome can be improved with use of a multidisciplinary approach for management involving an obstetrician who has specialized in high-risk pregnancies, a rheumatologist, and a pediatrician. ${ }^{32}$

\section{Hashimotos thyroiditis}

Hashimotos thyroiditis is associated with an increase rate of spontaneous.

Abortions, preterm delivery and increased use of cesarean section. ${ }^{33}$ All the three patients diagnosed with Hashimotos thyroiditis underwent cesarean section for non-progression of labour.

\section{Ulcerative colitis}

Stephansson et al study concluded that pregnant women with ulcerative colitis had a greater number of preterm births, babies with low birth weight and cesarean section deliveries than those without ulcerative colitis. ${ }^{34}$ In our study we had one patient who delivered a low birth weight baby of $2.2 \mathrm{~kg}$. One patient diagnosed with multisystem connective tissue disorder had an intra uterine growth restriction and the same baby had low birth weight.

\section{Von Willebrand's disease}

Pregnancy and delivery are considered events predisposing to a high risk of bleeding in women with von Willebrand's disease. ${ }^{35}$

Our patient did not have any complication. All the patients diagnosed with GDM were found to be on steroids.

Among the 113 patients, 3 underwent caesarean section in view of abnormal umbilical artery doppler findings.

Patients previously diagnosed were continued on disease modifying agents and this could be the reason for their successful pregnancy outcome.

Rauto immune disorders were diagnosed before pregnancy and these pregnancies were managed by multidisciplinary approach, and continued on immune modulators throughout the pregnancy, hence minimizing maternal and fetal complications.

\section{CONCLUSION}

In our study, most of the patients were either continued on the same treatment they were taking before pregnancy or were started on treatment once they were diagnosed with autoimmune disorders, and hence they were found to have successful pregnancy outcomes. Therefore, appropriate pre-conceptional counselling, continuation of treatment, intense maternal and fetal monitoring and timely delivery plays an important role in improving the pregnancy outcome.

\section{Funding: No funding sources}

Conflict of interest: None declared

Ethical approval: The study was approved by the Institutional Ethics Committee

\section{REFERENCES}

1. Sarah M, Mark Q, Paul E, Chapter 32 - Rheumatoid arthritis Editors: Noel R. Rose, Ian R. Mackay, The Autoimmune Diseases. $4^{\text {th }} \mathrm{Ed}$, Academic press; 2006:417-436.

2. Cooper G, Bynum M, Somers E. Recent insights in the epidemiology of autoimmune diseases: improved prevalence estimates and understanding of clustering of diseases. J Autoimmun. 2009;33(3-4):197-207.

3. Perricone C, Carolis C, Perricone R. Pregnancy and autoimmunity: a common problem. Best Pract Res Clin Rheumatol. 2012;26(1):47-60. 
4. Andreoli L, Fredi M, Nalli C, Reggia R, Lojacono A, Motta $\mathrm{M}$ et al. Pregnancy implications for systemic lupus erythematosus and the antiphospholipid syndrome. J Autoimmun. 2012;38(2-3):197-208.

5. Mecacci F, Pieralli A, Bianchi B, Paidas MJ. The impact of autoimmune disorders and adverse pregnancy outcome. Semin Perinatol. 2007;31(4):223-6.

6. Wilson WA, Gharavi AE, Koike T. International consensus statement on preliminary classification criteria for definite antiphospholipid syndrome: report of an international workshop. Arth Rhe. 1999;42:1309-11.

7. Miyakis S, Lockshin MD, Atsumi T. International consensus statement on an update of the classification criteria for definite antiphospholipid syndrome (APS). J Thromb Haemost. 2006;4:295306.

8. Hughes GR. The antiphospholipid syndrome: ten years on. Lancet (London, England). 1993;342:3414.

9. Lockshin MD, Kim M, Laskin Ca. Prediction of adverse pregnancy outcome by the presence of lupus anticoagulant, but not anticardiolipin antibody, in patients with antiphospholipid antibodies. Arth Rh. 2012;64:2311-8.

10. Wijeyaratne CN, Galappaththi SLA, Palipane E, Jayawardane DBIA, Dodampahala SH, Tudawe MN, et al. Pregnancy outcomes of antiphospholipid syndrome: In a low resource South Asian setting. Med. 2016;9(2):83-9.

11. Cooper GS, Gilbert KM, Greidinger EL. Recent advances and opportunities in research on lupus: environmental influences and mechanisms of disease. Environ Health Perspect. 2008;116:695-702.

12. Clowse MEB, Jamison M, Myers E. A national study of the complications of lupus in pregnancy. Am J Obstet Gynecol. 2008;199:1-12.

13. Jakobsen IM, Helmig RB, Stengaard-Pedersen K. Maternal and foetal outcomes in pregnant systemic lupus erythematosus patients: an incident cohort from a stable referral population followed during 1990-2010. Scand J Rheumatol. 2015;44:377-84.

14. Eman Aly, Hussein Aly, Riyad RM, Mokbel AN. Pregnancy outcome in patients with systemic lupus erythematosus: a single center study in the high-risk Pregnancy unit. Middle East Fert Society J. 2016;21:168-74.

15. Mandal D, Mandal S, Dattaray C, Banrrjee D, Ghosh $\mathrm{P}$, Ghosh A, et al. Takayasu arteritis in pregnancy: an analysis from eastern India. Arch Gynecol Obstet. 2012;285(3):567-71.

16. Jennette CJ, Milling DM, Falk RJ. Vasculitis affecting the skin. Arch Dermatol. 1994;130:899-906.

17. Robert F, Walter R, Sator PG, Gschnait F, Breier F. Schönlein-Henoch purpura during pregnancy with successful outcome for mother and newborn BMC Dermatol. 2002;2:1.

18. Gatto M, Iaccaino L, Canova M, Nalotto L, Ramonda R. Pregnancy and vasculitis; a systematic review of the literature. Autoimmun Rev. 2012;11:A447-59.

19. Wyszynski DF, Carman WJ, Cantor AB, Graham JM, Kunz LH, Slavotinek AM, et al. Pregnancy and birth outcomes among women with idiopathic thrombocytopenic purpura. J Preg. 2016:Article id 8297407.

20. Yassaee F, Eskandari R, Amiri Z. Pregnancy outcomes in women with idiopathic thrombocytopenic purpura. Iran J Reprod Med. 2012;10(5):489-92.

21. De Man YA, Hazes JMW, Van Der Heide H. Association of higher rheumatoid arthritis disease activity during pregnancy with lower birth weight: Results of a national prospective study. Arth Rhe. 2009;60:3196-206.

22. Bharti B, Lee SJ, Lindsay SP. Disease severity and pregnancy outcomes in women with rheumatoid arthritis: Results from the organization of teratology information specialists autoimmune diseases in pregnancy project. J Rheumatol. 2015;42:1376-82.

23. Hughes RA, Cornblath DR. GuillainBarre' syndrome. Lancet. 2005;366:1653-66.

24. Vijayaraghavan J, Vasudevan D, Sadique N, Rajeswari KS, Pondurangi M, Jayshree A. Rare case of Guillain-Barre' syndrome with pregnancy. J Indian Med Assoc. 2006;104:269-70.

25. Coles A. Multiple sclerosis. Lancet. 2008;372:1502-17.

26. Jalkanen A, Alanen A, Airas L. The finnish multiple sclerosis and pregnancy study group. Pregnancy outcome in women with multiple sclerosis - results from a prospective nationwide study in Finland. Mult Scler. 2010;16:950-5.

27. Mueller BA, Zhang J, Critchlow CW. Birth outcomes and need for hospitalization after delivery among women with multiple sclerosis. Am J Obstet Gynecol. 2002;186:446-52.

28. Dahl J, Myhr KM, Daltveit AK, Hoff JM, Gilhus NE. Pregnancy, delivery, and birth outcome in women with multiple sclerosis. Neurol. 2005;65:1961-3.

29. Siamopoulou-Mavridou A, Manoussakis MN, Mavridis AK, Moutsopoulos HM. Outcome of pregnancy in patients with autoimmune rheumatic disease before the disease onset. Ann Rheum Dis. 1988;47(12):982-7.

30. Carvalheiras G, Faria R, Braga J, Vasconcelos C. Fetal outcome in autoimmune diseases. Autoimmun Rev. 2012;11(6-7):A520-30.

31. Sandhya P, Jeyaseelan L, Scofield RH, Danda D. Clinical characteristics and outcome of primary Sjogren's syndrome: a large Asian Indian cohort. Open Rheumatol J. 2015;9:36-45.

32. Brucato A, Cimaz R, Caporali R, Ramoni V, Buyon J. Pregnancy outcomes in patients with autoimmune diseases and anti-Ro/SSA antibodies. Clin Rev Allergy Immunol. 2011;40(1):27-41.

33. Lao TT. Thyroid disorders in pregnancy. Curr Opin Obstet Gynecol. 2005;17:123-7. 
34. Stephansson O, Larsson H, Pedersen L. Congenital abnormalities and other birth outcomes in children born to women with ulcerative colitis in Denmark and Sweden. Inflamm Bowel Dis. 2011;17(3):795-801.

35. Kujovich JL. Von Willebrand disease and pregnancy. J Thromb Haemost. 2005;3(2):246-53.
Cite this article as: Maheswari $\mathrm{S}$, Poornima $\mathrm{C}$, Panicker S. Review of 113 cases of autoimmune disorders in pregnancy. Int J Reprod Contracept Obstet Gynecol 2019;8:4786-92. 